\title{
Fenotipagem de precisão na cultura do amendoim para detecção de déficit hídrico
}

Submetido - 30 jul. $2020 \quad$ Aprovado - 09 set. $2020 \quad$ Publicado - 14 out. 2020
doI ${ }_{\text {http://dx.doi.org/10.17648/sas.v1i2.64 }}$

\author{
Mestranda em Genética e Melhoramento de Plantas, \\ analiracosta@gmail.com.
}

\section{RESUMO}

O amendoim é uma oleaginosa conhecida por conter potencial para ser cultivado em áreas com menor disponibilidade hídrica, entretanto quando submetida à condição de estresse ao déficit hídrico, ocasiona mudanças no sistema fisiológico e bioquímico como fechamento dos estômatos que reduz a transpiração e, consequentemente, o suprimento de $\mathrm{CO}_{2}$ para a fotossíntese, que dependendo das condições de manejo estes danos podem ser irreversíveis. Desta forma, a procura por cultivares com melhor desempenho agronômico geral em regiões com maior limitação hídrica é cada vez maior, levando melhoristas expandirem seus experimentos buscando metodologias que reduza o tempo entre a pesquisa e a introdução dos seus resultados no mercado. Uma das alternativas de otimização experimental em larga escala e de alta qualidade é a fenotipagem por meio de imagens. Esta técnica abordada pela fenômica avalia com eficiência imagens digitais de alta qualidade dos experimentos em campo através de Veículos Aéreos Não Tripulados (VANTs), obtendo dados mediante análises digitais correlacionadas às bibliotecas de processamento digital de imagens. Ao se obter estes dados torna-se a mensuração da fenotipagem mais precisa em relação aos descritores com medidas manuais. $\quad 0$ objetivo deste trabalho é avaliar a eficiência da fenotipagem no cultivo do amendoim através de imagens digitais, garantindo precisão e praticidade para pesquisas futuras.

Palavras-chave: Arachis hypogaea L.; Método não-destrutível; Estresse hídrico; VANTs.

\section{Precision phenotyping in peanut culture to detect water deficit}

\section{ABSTRACT}

Peanuts are an oilseed known to contain the potential to be cultivated in areas with less water availability, however when subjected to the condition of stress to water deficit, it causes changes in the physiological and biochemical system, such as stoma closure, which reduces sweating and, consequently, supply of $\mathrm{CO}_{2}$ for photosynthesis, which, depending on the management conditions, these damages may be irreversible. Thus, the demand for cultivars with better overall agronomic performance in regions with greater water limitation is increasing, leading breeders to expand their experiments looking for methodologies that reduce the time between research and the introduction of their results in the market. One of the alternatives for large-scale, high-quality experimental optimization is phenotyping by means of images. This technique approached by phenomics efficiently evaluates high-quality digital images from field experiments through Unmanned Aerial Vehicles (UAVs), obtaining data through digital analyzes correlated to digital image processing libraries. When obtaining these data, the measurement of phenotyping becomes more accurate in relation to the descriptors with manual measurements. The objective of this work is to evaluate the efficiency of phenotyping in the cultivation of peanuts through digital images, ensuring precision and practicality for future research.

Keywords: Arachis hypogaea L.; Hydrical stress; Non-destructive tool; UAVs. 


\title{
Fenotipado de precisión en cultivos de maní para detectar déficit hídrico
}

\author{
RESUMEN
}

\begin{abstract}
El maní es una oleaginosa conocida por tener el potencial de ser cultivada en áreas con menor disponibilidad de agua, sin embargo, cuando se somete a la condición de estrés por déficit hídrico, provoca cambios en el sistema fisiológico y bioquímico, como el cierre del estoma, lo que reduce la sudoración y, en consecuencia, suministro de $\mathrm{CO}_{2}$ para la fotosíntesis, que dependiendo de las condiciones de manejo, estos daños pueden ser irreversibles. Así, la demanda de cultivares con mejor desempeño agronómico general en regiones con mayor limitación hídrica está aumentando, lo que lleva a los fitomejoradores a expandir sus experimentos buscando metodologías que reduzcan el tiempo entre la investigación y la introducción de sus resultados en el mercado. Una de las alternativas para la optimización experimental a gran escala y de alta calidad es el fenotipado mediante imágenes. Esta técnica abordada por la fenómica evalúa de manera eficiente imágenes digitales de alta calidad de experimentos de campo a través de vehículos aéreos no tripulados (UAV), obteniendo datos mediante análisis digitales correlacionados con bibliotecas de procesamiento de imágenes digitales. Al obtener estos datos, la medida de fenotipado se vuelve más precisa en relación a los descriptores con medidas manuales. El objetivo de este trabajo es evaluar la eficiencia de la fenotipificación en el cultivo de maní a través de imágenes digitales, asegurando precisión y practicidad para futuras investigaciones.
\end{abstract}

Palabras clave: Arachis hypogaea L.; Método no destructible, Estrés hídrico, UAV.

\section{Introdução}

O cultivo do amendoim (Arachis hypogaea L.) passou ao longo dos anos por várias mudanças em sua cadeia produtiva, tornando-se uma das oleaginosas mais importantes no mundo. Contextualizando o panorama mundial, China, Índia e Estados Unidos lideram o mercado de exportação. Na América Latina o mercado é liderado pela Argentina com produção de aproximadamente 1 milhão de toneladas, colocando o Brasil na segunda posição como produtor e exportador de amendoim, com 558 mil toneladas, sendo $90 \%$ dessa produção cultivada no Estado de São Paulo (CONAB, 2020).

O cultivo do amendoim detém também grande importância socioeconômica pois sua utilização é amplamente diversificada, tendo seu grão elevado valor nutricional. Considerada uma cultura rustica, seus grãos possuem alto valor proteico (22 a 30\%), rico em óleo (aproximadamente $50 \%$, carboidratos, sais minerais e vitaminas, destacando-se como matériaprima promissora para a produção de biodiesel (SANTOS, 2013). 
Dentre as oleaginosas, o amendoim possui maior relevância pois seu cultivo é de dispersão cosmopolita, devido principalmente à sua adaptabilidade à diversas condições ambientais e capacidade de cultivo anual de ciclos precoce de 90 a 110 dias de até três vezes ao ano dependendo da disponibilidade hídrica, sendo imprescindível aliar-se da multidisciplinaridade da pesquisa para viabilização de seu cultivo (PEREIRA et al., 2012).

A otimização dos processos de fenotipagem vem de encontro ao desafio do desenvolvimento de cultivares mais precoces que apresentem além de bom desempenho em condições de déficit hídrico, combinem resistência à pragas, doenças e padrão de grão que atenda indústria e exportação (CHEN et al., 2019).

Ao adotar esta metodologia tecnológica, através de métodos não destrutíveis, ou minimamente invasivos, os programas de melhoramento utilizam conhecimentos e progressos de diversas áreas permitindo antecipação das soluções de problemas, reunindo periodicamente atualizações de métodos capazes de analisar desde o topo até as raízes da planta sem agredi-la, como parte integrante das ações de planejamento da escolha das melhores variedades, viabilizando suas futuras produções (FRITSCHE-NETO; MATIAS, 2016).

\section{Material e métodos}

A fenotipagem tradicional consiste em fazer análise planta por planta, ocasionando invariavelmente danos em algumas plantas na parcela, leva-se também em consideração o critério individual do melhorista, dando margem à erros perante a avaliação (CORTES et al., 2017).

Conhecida como fenotipagem de alto desempenho, a aquisição das imagens digitais é considerada como uma análise óptica não destrutiva realizada através de equipamentos aéreos acoplados com câmeras, scanners, aparelhos de raios-X ou sensores térmicos (Figura 1) que permitem uma avaliação mais sensível das características vegetais para fenotipagem imediata e precisa, sendo ferramentas de fácil utilização com 
rápida resposta na detecção da ocorrência de estresse hídrico (SANTOS; RODRIGUES, 2016).

a)

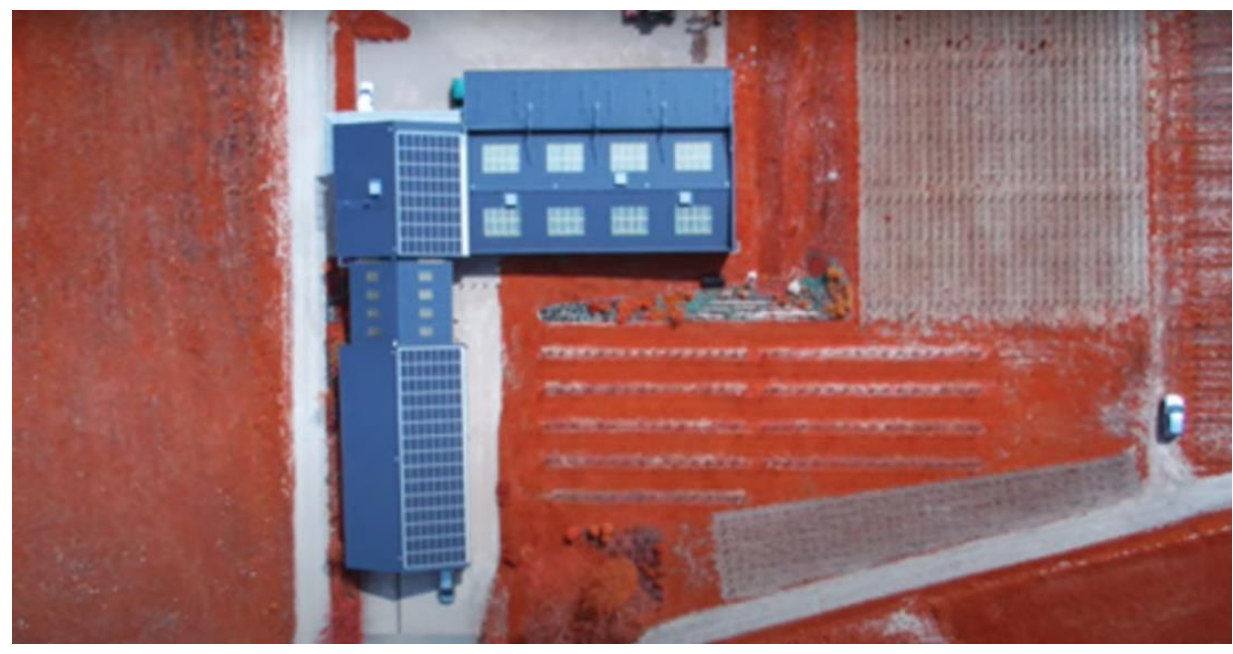

b)

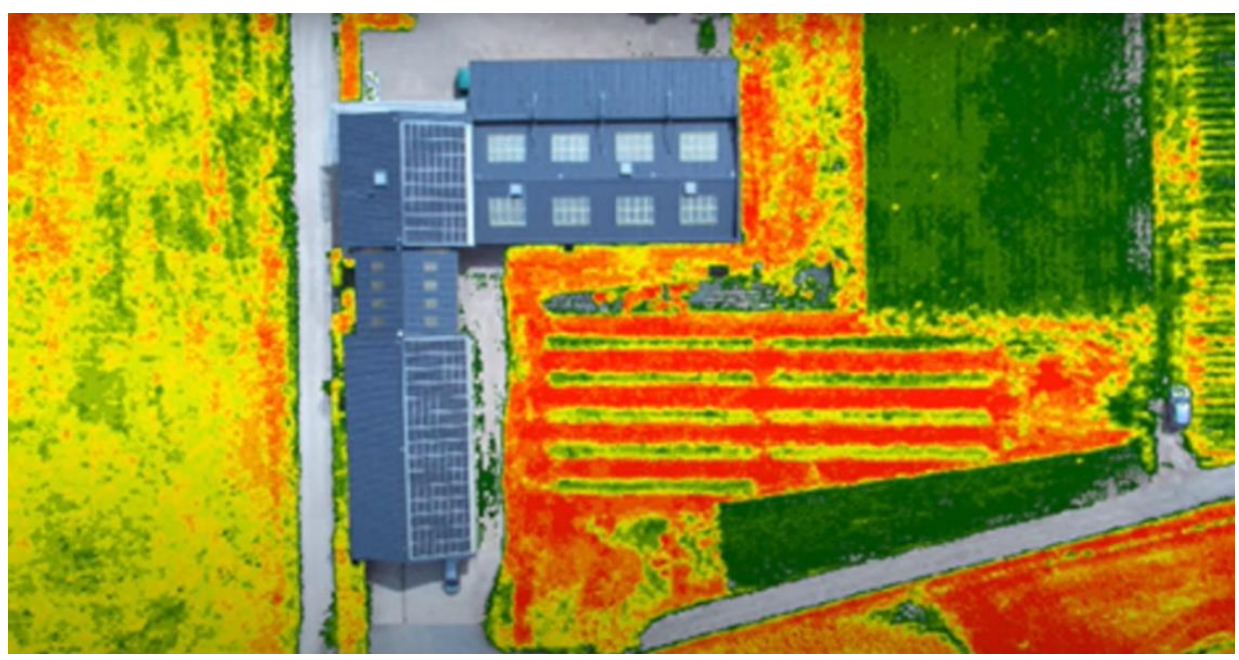

Figura 1. Processamento das imagens. a) pré-processamento b) pósprocessamento. Fonte: Adaptado de Muonray (2020).

A utilização de métodos ópticos para processamento de imagens como RGB (Red, Green and Blue), NIR (Near-Infrared), indução de fluorescência ou termometria infravermelha (Figura 2) que possibilita a medição da temperatura da porção superior do dossel vegetativo sem a necessidade de contato manual com as folhas, sintetizam técnicas necessárias para avaliar os fatores bióticos e abióticos da planta em seu ambiente, sem agredi-la e diminuindo o tempo para resolução dos complexos fatores envolvidos no melhoramento de plantas (GAGO et al., 2015). 


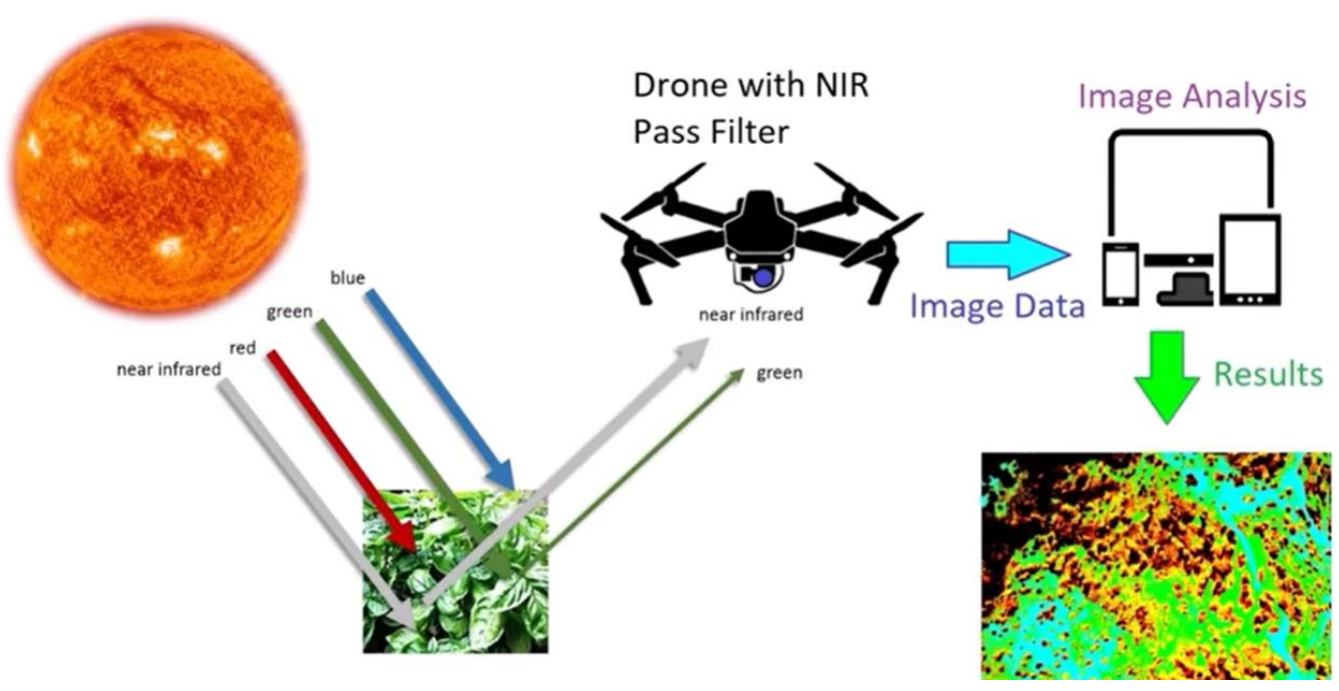

Figura 2. As refletividades atribuídas nos canais de cores no sensor da câmera quando equipado com os filtros. Fonte: Adaptado de Spectraldevices (2020).

sem agredi-la e diminuindo o tempo para resolução dos complexos fatores envolvidos

\section{Desenvolvimento do tema proposto}

Para correlação dos fatores envolvidos no processo de produção em influência na temperatura do dossel e disponibilidade hídrica, as avaliações são realizadas a cada fase de desenvolvimento fenológico do amendoim (Figura 3), através de Veículos Aéreos Não Tripulados (VANTs) permitindo a medição de grandes áreas cultivadas (ZHANG, 2019).

A utilização da termometria de infravermelho na determinação do índice de estresse hídrico (IEHC) do amendoim sinaliza o momento ideal para a irrigação da cultura. Com dados coletados através deste índice é possível obter a taxa e o padrão de estresse hídrico ao longo do ciclo ou em algum dia específico.

O IEHC é específico para cada cultura, assim, Idso et al. (1981) e Jackson (1981) determinaram equação para a cultura do amendoim. Para esta determinação cada parcela da superfície estudada deve ser monitorada através de aparelhos acoplados com termômetro de infravermelho com medição da temperatura da cobertura vegetal e da temperatura do ar (Figura 4). 


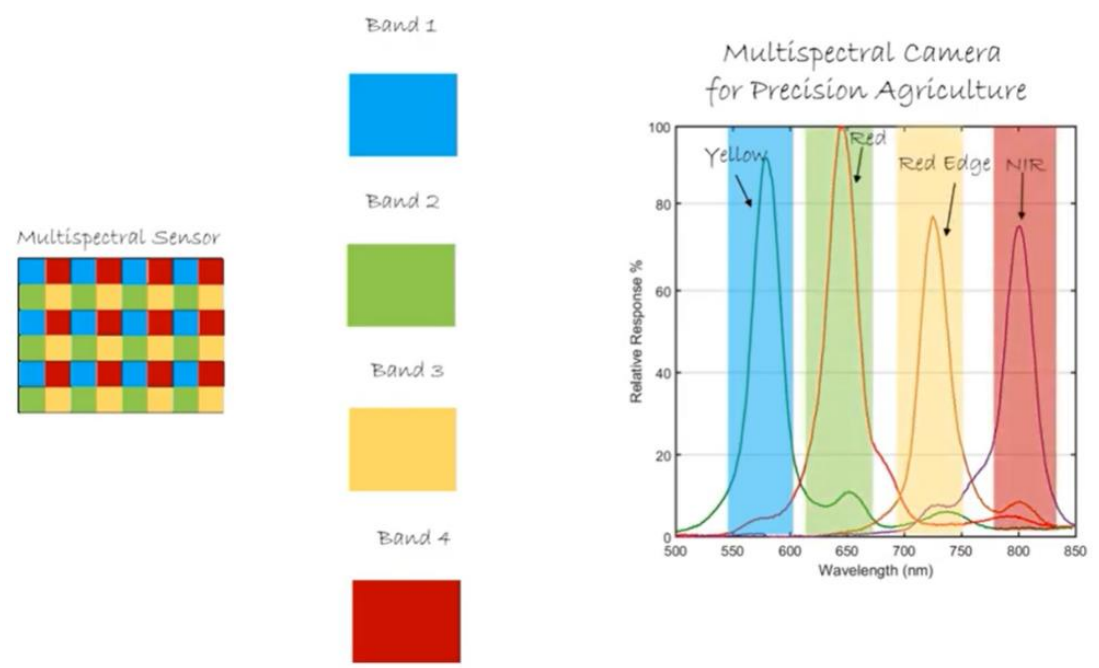

Figura 3. Comparativo entre os comprimentos de ondas dos métodos. Fonte: Adaptado de Spectraldevices (2020).

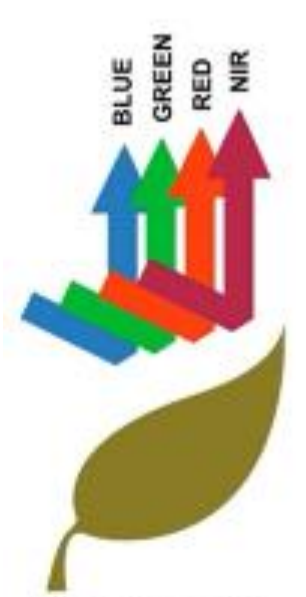

Dead Leaf

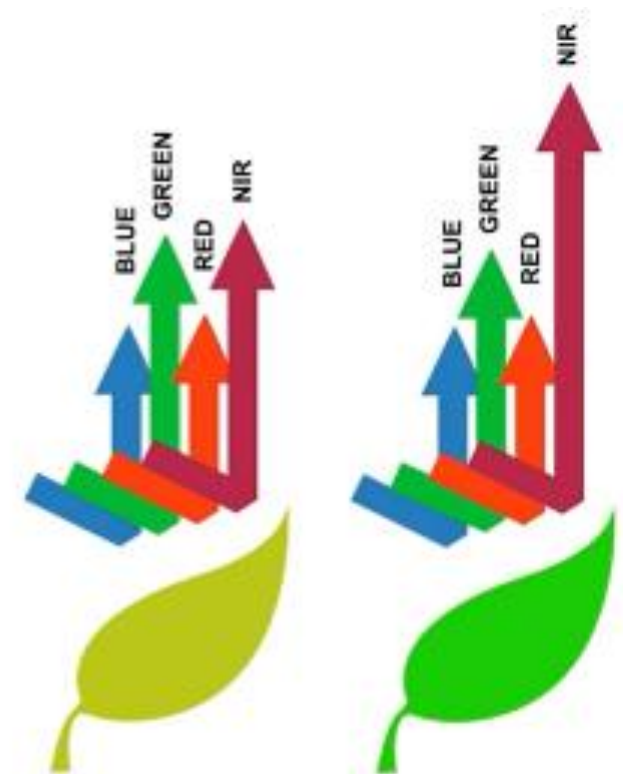

Stressed Leaf Healthy Leaf

Figura 4. Comparativo da reflectância entre as fases de desenvolvimento da cultura. Fonte: Adaptado de BigYield (2020).

Corroborando Fernandes (2010), um valor de IEHC positivo, indica que a cultura está sob estresse, conforme proposto por Idso et al. (1981) e Jackson et al. (1981) o cálculo é realizado pela diferença entre as temperaturas médias da cobertura vegetal $\left(\mathrm{Ts} \mathrm{em}^{\circ} \mathrm{C}\right)$, e as temperaturas médias do $\operatorname{ar}\left(\mathrm{Ta} \mathrm{em}^{\circ} \mathrm{C}\right)$ sendo expressa:

$\mathrm{IEHC}=\mathrm{Ts}-\mathrm{Ta}$

Em que: 
IEHC = índice de estresse hídrico $\left({ }^{\circ} \mathrm{C}\right)$;

Ts = temperatura média do dossel $\left({ }^{\circ} \mathrm{C}\right)$;

$\mathrm{Ta}=$ temperatura média do ar $\left({ }^{\circ} \mathrm{C}\right)$.

Para evitar eventuais erros amostrais, é necessário realizar as leituras com o sensor do aparelho posicionado em direção oposta ao sol (FERNANDES; TURCO, 2001), bem como evitar dias de precipitações, ocorrência de vento forte (observação visual), e ou tempo nublado impedindo o fluxo de radiação solar direta e outras recomendações de acordo com a limitação do aparelho e da metodologia.

\section{Considerações finais}

Embora os progressos já apresentados na área, a fenotipagem de alto desempenho é uma metodologia ainda recente. Assim, é importante o desenvolvimento constante de novas técnicas, novos sensores e enfoque multidisciplinar, como o uso de técnicas avançadas de genotipagem visando diminuir o tempo de pesquisa e desenvolvimento, com mais qualidade e produtividade. 


\section{Referências}

BIGYIELD. How Does NIR Imaging and Drone Technology Help Farmers. Disponivel em: https://www.bigyield.us/how-does-nir-imaging-and-dronetechnology-help-farmers/. Acesso em: 15 de agosto 2020.

CHEN, A.; ORLOV-LEVIN, V.; MERON, M. Applying high-resolution visiblechannel aerial imaging of crop canopy to precision irrigation management. Agricultural water management, v. 216, p. 196-205, 2019.

CONAB, Companhia Nacional de Abastecimento. Acompanhamento da safra brasileira - Grãos. v. 7 - Safra 2019/20- N. 9 - Nono levantamento, Junho 2020. Disponível em www.conab.gov.br. Acesso: 15 de julho 2020.

CORTES, D. F. M.; CATARINA, R. S.; BARROS, G. B. D. A.; ARÊDES, F. A. S.; SILVEIRA, S. F. D.; FERREGUETTI, G. A.; RAMOS, H. C. C.; VIANA, A. P.; PEREIRA, M. G. Modelassisted phenotyping by digital images in papaya breeding program. Scientia Agricola, v. 74, n. 4, p. 294-302, 2017.

FERNANDES, E. J. Determinação do índice de estresse hídrico em cultura do feijoeiro com termômetro de infravermelho. Irriga, Botucatu, v.15, n.3, p.248, 2010.

FERNANDES, E. J.; TURCO, J. E. P. Utilização do CWSI na determinação de estresse hídrico em cultura de soja. Revista Brasileira de Agrometeorologia, Santa Maria, v. 9, n. 2, p. 347-355, 2001.

FRITSCHE-NETO, R.; MATIAS, F.I. Be-Breeder-Learning: a new tool for teaching and learning plant breeding principles. Crop Breeding and Applied Biotechnology 16: 240-245, 2016.

GAGO, J.; DOUTHE, C.; COOPMAN, R.E.; GALLEGO, P.P.; RIBASCARBO, M.; FLEXAS, J.; ESCALONA, J.; MEDRANO, H. UAVs challenge to assess water stress for sustainable agriculture. Agricultural water management, v. 153, p. 9-19, 2015.

IDSO, S. B.; JACKSON, R. D.; PINTER JUNIOR, P. J.; REGINATO, R. J.; HATFIELD, J. L. Normalizing the stress-degree-day parameter for environmental variability. Agricultural Meteorology, Phoexix - Arizona, v. 24, n. 1, p. 45-55, 1981.

JACKSON, R.D.; IDSO, S.B.; REGINATO, R.J.; PINTER JR.; P.J. Canopy temperature as a crop water stress indicator. Water Conservation Laboratory, Phoenix - Arizona, v. 17, n.1, p.1133-1138, 1981.

MUONRAY. Drone-Based Vegetation Index using Custom Near-Infrared (NIR) Filters. Disponível em:https://muonray.blogspot.com/2018/11/dronebased-vegetation-index-using.html. Acesso em: 15 ago. 2020.

PEREIRA, J. W. L.; MELO-FILHO, P. A.; ALBUQUERQUE, M. B.; NOGUEIRA, R. J. M. C.; SANTOS, R. C. Mudanças bioquímicas em 
genótipos de amendoim submetidos a déficit hídrico moderado. Revista Ciência Agronômica, 43(4), p. 766-773, 2012.

SANTOS, R.C.; FREIRE, R.M.M.; LIMA, L.M.; O Agronegócio do Amendoim no Brasil, 2 ed. Embrapa, Brasília, 2013.

SANTOS, T.T.; RODRIGUES, G. C., Flexible three-dimensional modeling of plants using lowresolution cameras and visual odometry. Journal of Machine Vision and Applications, 27(5), 695-707, 2016.

SPECTRALDEVICES. Multispectral Camera Technology. Disponível em: http://www.spectraldevices.com/content/multispectral-imaging-technology. Acesso em: 15 ago. 2020.

ZHANG, L.; ZHANG, H.; NIU, Y.; HAN, W. Mapping Maize Water Stress Based on UAV Multispectral Remote Sensing. Remote Sensing, v. 11, n. 6, p. 605, 2019. 